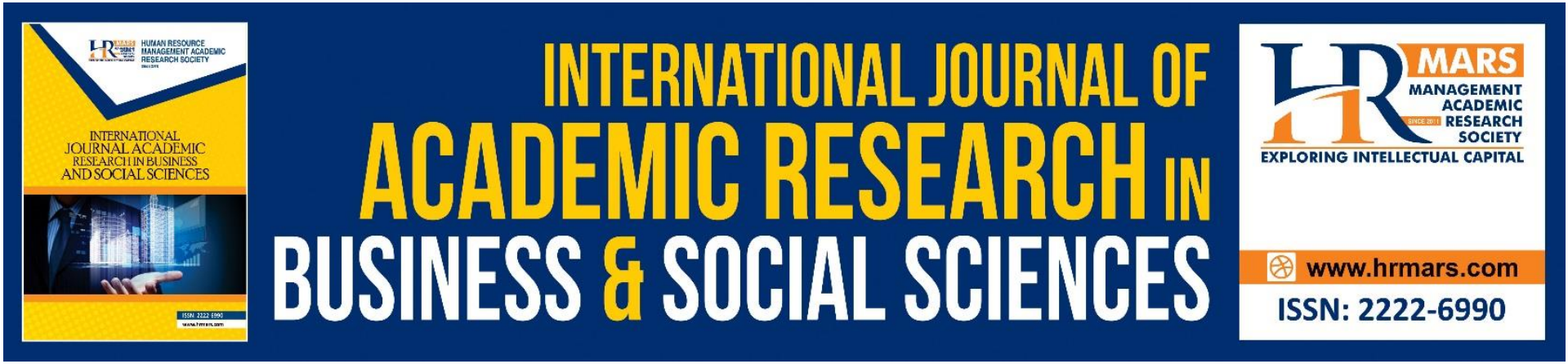

\title{
Reliability and Validity of the Malay Version of Mental Health Inventory-18
}

Hazalizah Hamzah, Siti Aishah Panatik, Asma Perveen, Fatanah Ramlee

To Link this Article: http://dx.doi.org/10.6007/IJARBSS/v12-i2/12276

DOI:10.6007/IJARBSS/v12-i2/12276

Received: 20 December 2021, Revised: 23 January 2022, Accepted: 08 February 2022

Published Online: 28 February 2022

In-Text Citation: (Hamzah et al., 2022)

To Cite this Article: Hamzah, H., Panatik, S. A., Perveen, A., \& Ramlee, F. (2022). Reliability and Validity of the Malay Version of Mental Health Inventory-18. International Journal of Academic Research in Business and Social Sciences, 12(2), 216-228.

Copyright: (c) 2022 The Author(s)

Published by Human Resource Management Academic Research Society (www.hrmars.com)

This article is published under the Creative Commons Attribution (CC BY 4.0) license. Anyone may reproduce, distribute, translate and create derivative works of this article (for both commercial and non0-commercial purposes), subject to full attribution to the original publication and authors. The full terms of this license may be seen at: http://creativecommons.org/licences/by/4.0/legalcode

Vol. 12, No. 2, 2022, Pg. $216-228$

Full Terms \& Conditions of access and use can be found at http://hrmars.com/index.php/pages/detail/publication-ethics 


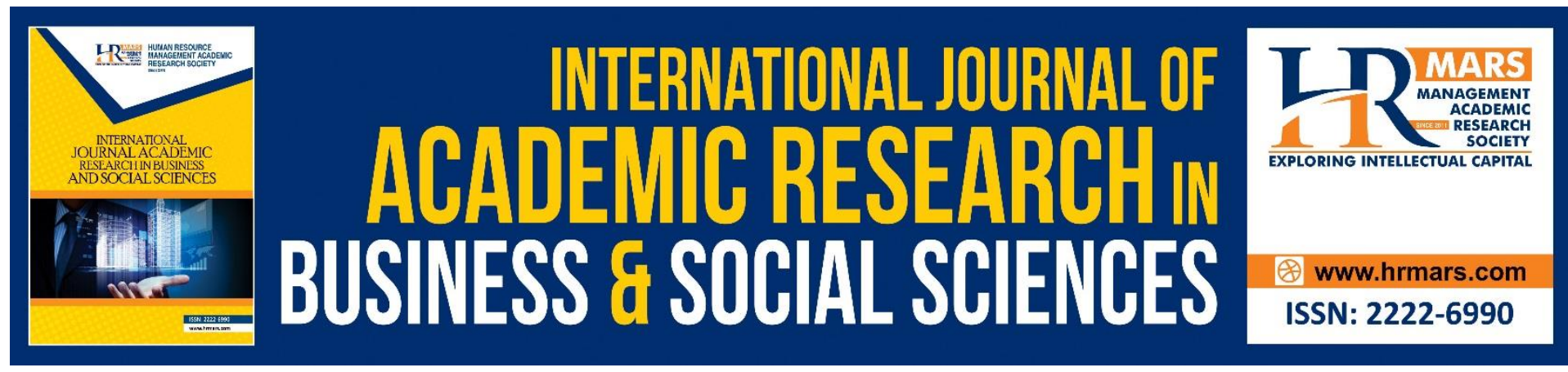

\title{
Reliability and Validity of the Malay Version of Mental Health Inventory-18
}

\author{
Hazalizah Hamzah¹, Siti Aishah Panatik², Asma Perveen ${ }^{1}$, \\ Fatanah Ramlee ${ }^{1}$ \\ ${ }^{1}$ Department of Psychology and Counseling, Sultan Idris Education University, 35900, \\ Malaysia, ${ }^{2}$ School of Human Resource Development and Psychology, University of \\ Technology Malaysia, 81310, Malaysia \\ Email: hazalizah@fpm.upsi.edu.my
}

\begin{abstract}
Beginning of the COVID-19 pandemic, mental health issues have been prominent discussions worldwide. People are more aware of their mental health status as well as their loved ones. Besides having sound psychometric properties, a good instrument to measure mental health status accurately should be language-friendly. Hence, the 18-item Mental Health Inventory (MHI-18) was back-to-back translated into Malay Language and its reliability and validity properties were investigated. A total of 569 Malaysian adults (73.8\% females), $M_{\text {age }}=21.73$, $S D_{\text {age }}=2.59$ participated in an online survey during the pandemic. From the analysis, two items with low factor loadings were deleted. The remaining 16 items successfully loaded on two factors, namely Psychological Distress $(C R=0.89)$ and Psychological Well-being $(C R=$ 0.90). The results supported convergent and discriminant validity. Thus, the Malay Language version of $\mathrm{MHI}$ with 16 items is a reliable and valid mental health instrument for the Malayspoken adult population.
\end{abstract}

Keywords: Mental Health Measurement, Psychometrics, Malay Version, Reliability, Validity, $\mathrm{MHI}-18$

\section{Introduction}

According to the World Health Organization (WHO), mental health is "a state of well-being in which the individual realizes his or her abilities, can cope with the normal stresses of life, can work productively and fruitfully, and can make a contribution to his or her community" (World Health Organization, 2018). Since the beginning of the COVID-19 pandemic, mental health issues have been a prominent interest worldwide. An uncountable individual has lost their sources of income because of the pandemic and struggling for necessities, and these uncertainties of the future have led to symptoms of mental illness, such as anxiety and depression (Kumar \& Nayar, 2021). Along the same line, an individual's social lifestyle showed connections with the feelings of loneliness during the pandemic. It is speculated that individuals with active social life will have a higher tendency to be negatively impacted during the pandemic compared to those with passive social life (Dahlberg, 2021). 
Besides experiencing a lower quality of life, individuals from several countries also had to bear higher levels of emotional distress and loneliness because of COVID-19 (Geirdal et al., 2021) and recently, people are becoming more aware of their mental health status, as well as their loved ones. Kumar and Nayar (2021) discussed the importance of providing psychosocial support and assistance particularly for children who are miserably impacted by the COVID-19 pandemic as they respond to stress in various ways. In addition, they require love and attention from older individuals during these tough times. In addition, Smith et al (2021) suggested interventions to raise mental health awareness such as health promotion conducted in groups or classes, and a strong support system proved to be useful for women and pregnant women in managing their emotional well-being, stress and maintaining a healthy lifestyle during the pandemic. Young individuals may benefit more by receiving mental health assistance through the online method as it provides anonymity, privacy and is easier to express and share their problems with those in a similar situation (Leijdesdorff et al., 2021).

Therefore, it is important to have a list of instruments measuring mental health with sound psychometric properties. There are several options of good instruments for mental health measurement. For example, Ryff Scales of Psychological Well-being is the medium version of the instrument with 54 items from the original 84 items. The Ryff scale measures six domains of psychological well-being, namely autonomy, environmental mastery, personal growth, positive relations with others, purpose in life and self-acceptance (Seifert, 2005). Besides that, another tool for measuring mental health is the Positive Mental Health Instrument (PMHI), which has six dimensions including general coping, emotional support, spirituality, interpersonal skills, personal growth and autonomy, and finally, global effect. Altogether, PMHI comprises 47 items (Vaingankar et al., 2020). Lastly, Mental Health Inventory (MHI-38) is an inventory with 38 items that are used to measure psychological distress and well-being. MHI-38 consists of five dimensions, which measures Anxiety, Depression, Emotional Ties, General Positive Effect, and Loss of Behavioural Emotional Control (Veit \& Ware, 1983).

Despite being reliable and valid, those instruments are a bit lengthy and are unsuitable for the Malaysian population whose native language is the Malay language. For a quick record, as of the final quarter of 2021, Malaysia ranks at number 20 in the Worldometer for total Coronavirus cases, making Malaysia among the top 20 countries with the most daily cases reported (Worldometer, 2021). Although the curve is declining, the number of cases is still high and peoples' mental health is seriously affected. There has been an alarming increase in cases reported to the government concerning mental health, and from 2020 to $2021,85.5 \%$ of cases reported were related to mental health issues that require emotional support and counselling such as suicidal behaviour, stress, depression and abuse (Roslan, 2021). Up to July 2021 , there has been a total of 638 suicide cases, an increase of $143 \%$ compared to 2020 with 262 cases relating to suicide (Abdullah, 2021).

The Malaysia Ministry of Health has been aware of the increasing number of mental health cases since the pandemic started, and has taken several measures to help improve Malaysian's psychological well-being, such as introducing Psychosocial Support Helpline for the public, introducing Mental Health Psychosocial Support Service for certain target groups affected by COVID-19, psycho-education, mental health screening, and counselling (Kementerian Kesihatan Malaysia, 2021). Therefore, there is a need to have a good instrument to measure mental health status accurately for the Malaysian population and it has to be user-friendly for the respondents, particularly in terms of the language used. 
Veit and Ware (1983) developed MHI-38 to carefully measure mental health status. It consists of 38 items with five subscales, namely anxiety, depression, emotional ties, general positive effect, and behavioural emotional control, and two global scales, psychological distress and psychological well-being. Psychological well-being is characterized by a feeling of happiness which includes a sense of balance, vitality, feeling of self-worth, sense of mastery, self-efficacy, search for a new relationship and need of engaging in activities with people. On the other hand, psychological distress is typically observed in the feeling of anger, irritability, anxiety and exhaustion. People with high psychological distress tend to devalue, incline to isolate and not engage in activities with others for more than two weeks (Boas \& Morin, 2014).

MHI-38 has been widely used and translated into different languages. It was translated into the Arabic version and was named the Arabic Version of Mental Health Inventory-38 (AV-MHI-38). The AV-MHI-38 has an individual score of content validity ranging from 0.63 to 1.0, and has an $\alpha=0.85$ score for the whole questionnaire, after removing some unsuitable items (Al Mutair et al., 2018). Meanwhile, the Persian Version of MHI-38 shows that it has good internal consistency $(\alpha=0.83$ ) and test-retest reliability ( $\alpha=0.81)$, and after removing 7 items, considered as a suitable instrument to test the mental health of athletes (Mousavi et al., 2015). Hassani et al., (2013) utilized the MHI-38 in a study conducted for patients with heart failure, and the result has shown that MHI-38 has a good reliability with Cronbach's $\alpha=0.91$. Reyes et al (2017) investigated the mental health status of gifted adolescents in Filipino using MHI-38 and found good internal reliability, $\alpha=0.86$ for psychological distress, $\alpha=0.86$ for psychological well-being and $\alpha=0.89$ for Mental Health Index. Other research has found similar reliability values regarding MHI-38. Grijak (2017) obtained internal consistency of $\alpha=0.81$ for psychological distress, and $\alpha=0.75$ for psychological well-being.

More current research used the short-version of $\mathrm{MHI}-38$ i.e $\mathrm{MHI}-18$ which have been reported as reliable and valid too. Several studies have used MHI-18 in numerous settings, such as among university students (Rahman \& Ahmed, 2018), in medical students' population (Anjana et al., 2021), school students (Najma \& Sultan, 2021), individuals with sickle cell disease (Oyedeji et al., 2021), and among Filipinos adults (Antazo, 2020) to determine their mental health status.

It is important to note that $\mathrm{MHI}-18$ has been translated into various languages such as Urdu (Rafiq \& Sadiq, 2019), Persian (Meybodi et al., 2011), and Spanish (Mosher et al., 2010). Rafiq and Sadiq (2019) who conducted a study to understand the correlation between caregiver stress, the perceived stigma and mental health in female family members of drug addicts has adopted an Urdu version of $\mathrm{MHI}-18$ with a strong reliability coefficient of $\alpha=0.93$ for the overall scale. Similar to the Persian version, MHI-18 is considered to be valid and reliable to be used in the Iranian population with good reliability of $\alpha=0.93$, construct validity producing 2 factors, namely psychological distress and psychological well-being. The concurrent validity was tested using General Health Questionnaire (GHQ) and reported a negative correlation $(r=-.75)$, while reliability testing reported $\alpha=0.93$, and good internal consistency of anxiety $(\alpha=0.84)$, depression $(\alpha=0.83)$, behavioural control $(\alpha=0.63)$, and a positive effect $(\alpha=0.85$ ) (Meybodi et al., 2011). These findings are similar to the Spanish version of MHI-18 as the reliability of $\alpha$ is 0.92 (Mosher et al., 2010). In a nutshell, MHI-18 is found reliable and valid across cultures.

Mental health issues brought up by the COVID-19 pandemic has risen the demand for an instrument measuring mental health that is suitable for Malaysians. Therefore, $\mathrm{MHI}-18$ 
which has been proven as having sound psychometrics properties across cultures has been chosen to be back-to-back translated and validated for use among Malaysians in this research. Precisely, the two global scales of mental health, namely psychological distress and psychological well-being (Veit \& Ware, 1983) will also be tested.

\section{Method}

\section{Participant}

Respondents were 569 adults (male $n=149,26.2 \%$; female $n=420,73.8 \%$ ), age ranged from 18 to $35(M=21.73, S D=2.59)$. The majority of them were Malays $(n=377,66.3 \%)$, followed by Chinese $(n=68,12.0 \%)$, Indian ( $n=53,9.3 \%)$, Bumiputera Sabah $(n=54,9.5 \%)$, Bumiputera Sarawak $(n=7,1.2 \%)$, and Other Races $(n=10,1.8 \%)$. Convenience sampling has been utilized. Data was collected online during the COVID-19 pandemic in 2021 using Google Form, distributed via social media such as Facebook, WhatsApp, and Instagram. Respondents were informed that by submitting the completed survey form, they gave their consent for participation in the research. This research has received ethical approval from the Ethics Committee of Sultan Idris Education University.

\section{Material}

MHI-18, a simplified version of the original 38-item (Veit \& Ware, 1983) was used to measure mental health. It has two dimensions, psychological distress (e.g Item 14: Have you been in low or very low spirits? / Pernahkah anda berasa tidak bersemangat?) and psychological wellbeing (e.g. Item 15: Were you a happy person? / Adakah anda seorang yang gembira?), with 10 and 8 items respectively. All items under psychological well-being were reverse-scored (i.e Item 1, 3, 5, 7, 8, 10, 13, and 15). MHI-18 uses a 6-point Likert scale from 1 (all of the time) to 6 (none of the time). The higher total score of MHI-18 indicates a better mental health status. $\mathrm{MHI}-18$ was found valid and reliable in enormous studies (Meybodi et al., 2011). This study found that MHI-18 has sufficient internal consistency for total mental health score $(\alpha=0.873)$, psychological distress $(\alpha=0.887)$, and psychological well-Being $(\alpha=0.897)$. Apart from $\mathrm{MHI}-$ 18 , respondents also completed the demographic form.

MHI-18 was translated into Malay language using the back-to-back translation method (Brislin, 1970), which involved four steps. First, the original items (Version English A) were translated into Malay language (Version Malay A) by the first author. Second, Version Malay A was checked and verified by two native speakers of the Malay language. Third, Version Malay A was translated back into English by two English Language teachers (Version English B). Both Version English A and Version English B have compared if each item implies a different meaning and based on the result of the comparison, some minor changes were made to Version Malay A. Finally, the grammar aspects of Version Malay A was checked and validated by two lecturers teaching the Malay language. From now on, Version Malay $A$ is named Malay Version of Mental Health Inventory (MHI-Malay).

\section{Statistical Analysis}

Data were analyzed using IBM Statistical Package for Social Sciences version 25 (SPSS) and Structural Equation Modelling via IBM Analysis of Moment Structure version 24 (AMOS) software. Confirmatory Factor Analysis was run to find out the psychometric properties for MHI-Malay. 


\section{Result}

Prior to Confirmatory Factor Analysis (CFA), data were checked for missing value, normality, outliers and multicollinearity issues. Data had no missing value. As shown in Table 1, data were normally distributed with skewness and kurtosis values are within the range of \pm 2 (Garson, 2012b) and even less than \pm 1 (Tabachnick \& Fidell, 2007). Although the value of multivariate kurtosis was quite high, it is deemed acceptable (Gao, et. al, 2008). Checked using the SPSS, there was no z-score beyond \pm 4 , thus a major outlier was not an issue (Hair et al., 2010). In addition, the correlation between psychological well-being and psychological distress was $r=.25$, which is far below $r=.90$ (Hair et al., 2010) and the factor loadings were not close to 1.00 (Garson, 2012a). Therefore, multicollinearity was not a problem in this set of data. Based on this information, the data is considered suitable for model fit checking.

Table 1 Assessment of Normality

\begin{tabular}{lllllll}
\hline Variable & min & max & skew & c.r. & kurtosis & c.r. \\
\hline B2 & 1.000 & 6.000 & -.493 & -4.806 & .388 & 1.888 \\
B1 & 1.000 & 6.000 & .428 & 4.163 & -.246 & -1.197 \\
B3 & 1.000 & 6.000 & -.118 & -1.149 & -.692 & -3.368 \\
B5 & 1.000 & 6.000 & -.004 & -.041 & -.798 & -3.887 \\
B7 & 1.000 & 6.000 & -.062 & -.599 & -.623 & -3.033 \\
B8 & 1.000 & 6.000 & -.101 & -.987 & -.373 & -1.814 \\
B10 & 1.000 & 6.000 & .007 & .073 & -.711 & -3.460 \\
B13 & 1.000 & 6.000 & -.214 & -2.084 & -.319 & -1.551 \\
B15 & 1.000 & 6.000 & -.146 & -1.423 & -.558 & -2.718 \\
B4 & 1.000 & 6.000 & -.296 & -2.886 & -.147 & -.717 \\
B6 & 1.000 & 6.000 & -.356 & -3.463 & -.125 & -.611 \\
B9 & 1.000 & 6.000 & -.354 & -3.444 & -.156 & -.762 \\
B11 & 1.000 & 6.000 & -.217 & -2.113 & -.271 & -1.320 \\
B12 & 1.000 & 6.000 & -.345 & -3.362 & -.325 & -1.584 \\
B14 & 1.000 & 6.000 & -.449 & -4.371 & .154 & .749 \\
B16 & 1.000 & 6.000 & -.314 & -3.061 & -.287 & -1.397 \\
B17 & 1.000 & 6.000 & -.515 & -5.013 & -.087 & -.425 \\
B18 & 1.000 & 6.000 & -.509 & -4.960 & -.073 & -.354 \\
Multivariate & & & & & 106.35 & 47.275 \\
& & & & & 9 & \\
\hline
\end{tabular}

The summary of preliminary CFA results showed a significant chi-square value, $\chi^{2}(134)$ $=646.405, p=.0001$. This shows that the model does not fit the data well, however, this is common for a large sample size. The factor loadings were all above .50, except for item MHI16, whose factor loading was .39 (refer to Table 2). In addition, further observation showed that the model does not adequately fit the data as normed $\chi^{2}=4.824, \mathrm{CFI}=.898, \mathrm{TLI}$ $=.884, \mathrm{RMSEA}=.082$ and SRMR $=.0697$. In particular, CFI and TLI did not reach .90 and RMSEA was greater than .08 and therefore, a model modification was conducted to improve the goodness-of-fit (Garson, 2012a). The summary of model modifications is shown in Table 3. 
Table 2 Standardized Factor Loading

\begin{tabular}{lll}
\hline Item & Psychological Distress & Psychological Well-Being \\
\hline MHI18 & .802 & \\
MHI17 & .611 & \\
MHI16 & .388 & \\
MHI14 & .704 & \\
MHI12 & .718 & \\
MHI11 & .806 & \\
MHI9 & .715 & \\
MHI6 & .699 & \\
MHI4 & .605 & \\
MHI2 & .580 & \\
MHI15 & & \\
MHI13 & & .817 \\
MHI10 & & .840 \\
MHI8 & & .697 \\
MHI7 & & .742 \\
MHI5 & & .810 \\
MHI3 & & .653 \\
MHI1 & .638 \\
\hline
\end{tabular}

The summary of model modifications is shown in Table 3. In Model 2, item MHI16 was deleted due to low factor loading. However, the RMSEA value was still unsatisfactory. Thus, item MHI2 with the second-lowest factor loading had been deleted in Model 3. With remaining 16 items, the latest modified measurement model demonstrated a satisfactory model fit with a significant chi-square value, $\chi^{2}{ }_{(103)}=543.639, p=.0001$, normed $\chi^{2}=4.404$, $\mathrm{CFI}=.924, \mathrm{TLI}=.911, \mathrm{RMSEA}=.077$ and SRMR $=.0501$. Hence, the goodness-of-fit of the model is achieved and it is appropriate to proceed with reliability and validity assessment.

Table 3 Confirmatory Factor Analysis for MHI-Malay

\begin{tabular}{lcllllllll}
\hline Model & Item & $\begin{array}{l}\text { Facto } \\
\mathrm{r}\end{array}$ & CMIN(df) & AIC & CFI & TLI & SRMR & RMSEA & CMIN/df \\
\hline 1 & 18 & 2 & $\begin{array}{l}646.405 \\
(134)\end{array}$ & 756.405 & .898 & .88 & .0697 & .082 & 4.824 \\
2 & 17 & 2 & $\begin{array}{l}542.328 \\
(118)\end{array}$ & 646.328 & .913 & $\begin{array}{l}.90 \\
0\end{array}$ & .0618 & .080 & 4.596 \\
3 & 16 & 2 & $\begin{array}{l}543.639 \\
(103)\end{array}$ & 551.639 & .924 & $\begin{array}{l}.91 \\
1\end{array}$ & .0501 & .077 & 4.404 \\
\hline
\end{tabular}

Note. $\mathrm{CMIN}=$ Chi-square value; $\mathrm{CFI}=$ comparative fit index; $\mathrm{TLI}=$ Tucker-Lewis index; SRMR = standardized root mean square residual; RMSEA = root mean square error approximation; $\mathrm{CMIN} / d f=$ the minimal value of the discrepancy, $C$, divided by the degrees of freedom.

Table 4 depicted the CR and AVE values which show that the items of the MHI18Malay are consistently measured by both Psychological Distress and Psychological Well-being constructs. Furthermore, the convergent validity is evidenced as all the factor loadings are above $0.50, C R$ is above 0.70 , and AVE is more than 0.50 (Hair et al., 2010). As shown in Table 5 , the discriminant validity test is also confirmed for the values of the square root of AVE for both constructs are greater than the corresponding inter-construct correlations (Ramayah et 
al., 2018).

Table 4 Evaluation of Measurement Model 3

\begin{tabular}{lllll}
\hline Construct & Item & Loading & AVE & CR \\
\hline Psychological Distress & MHI18 & .817 & 0.505 & 0.890 \\
& MHI17 & .586 & & \\
& MHI14 & .694 & & \\
& MHI12 & .721 & & \\
& MHI11 & .815 & & \\
& MHI9 & .713 & & \\
& MHI6 & .702 & & \\
Psychological Well-Being & MHI4 & .602 & & \\
& MHI15 & .817 & 0.525 & 0.898 \\
& MHI13 & .841 & & \\
& MHI10 & .697 & & \\
& MHI8 & .741 & & \\
& MHI7 & .810 & & \\
& MHI5 & .653 & & \\
& MHI3 & .638 & & \\
& MHI1 & .601 & & \\
\hline
\end{tabular}

Table 5 Square-root of AVE for Psychological Distress and Psychological Well-being Psychological Distress Psychological Well-Being

Psychological Distress $\quad 0.711$

$\begin{array}{lll}\text { Psychological Well-Being } \quad 0.228 * * * & 0.725\end{array}$

Next, using the items of MHI-Malay the correlation between the total score of mental health with gender and age were found significant with $r_{(567)}=-.124, p=.003$ and $r_{(567)}=.229$, $p=.0001$, respectively. In particular, males and older adults have better mental health as compared to their counterparts. MHI-Malay successfully differentiate contrasted groups and these showed additional shreds of evidence for validity (Urbina, 2014).

\section{Discussion}

The objective of this article was to evaluate the psychometric properties of the Malay version of $\mathrm{MHI}-18$, a culture-proven measure of mental health worldwide. Based on the data of 569 Malaysian adult respondents, it is concluded that the Malay version of $\mathrm{MHI}-18$ which has been back-to-back translated is reliable and valid to be used on the intended population.

Due to poor factor loadings, two items were deleted (i.e Item 16 and Item 2). Although deleting items may decrease a measurement's content validity (Hair et al., 2014), the decision is deemed necessary as the two items are somewhat too general to measure mental health. Accordingly, CFA revealed a goodness-of-fit in Model 3 with two factors, namely psychological distress, and psychological well-being. Based on Veit and Ware (1983), these two factors are distinct and the practice of scoring them as separate factors is supported. 
With 16 remaining items, it is found that both psychological distress and psychological well-being constructs are consistent to measure mental health. This finding is comparable with those reported in previous research concerning the translated version of MHI-18 (Rafiq \& Sadiq, 2019; Meybodi et al., 2011; Mosher et al., 2010). Although there are five scales highlighted in MHI-38 (Veit \& Ware, 1983), they also found good support for the two facets. Both scales are different but complementary states of mental health (Massé et al., 1998).

In terms of validity, this research provided a good evaluation of both convergent and discriminant validity tests and these are also in line with other research conducted outside Malaysia (Antazo, 2020; Meybodi et al., 2011; Mosher et al., 2010; Rafiq \& Sadiq, 2019).

Significant relationships were found between mental health with gender and age and these findings are in the expected direction and accordance with previous research. For instance, past research reported that older people are having better mental health status (de Bruin, 2021; Every-Palmer et al., 2020; Wang et al., 2020; Li et al., 2021; Schweda et al., 2021; Wilson et al., 2021; Pieh et al., 2020). In addition, males are reported to have better mental health (Pieh et al., 2020; Burns et al., 2020; Wang et al., 2020; van Droogenbroeck et al., 2018; Burger \& Scholz, 2018; Abdel-Khalek \& Tekke, 2019).

These are due to older adults having more positive views on life and engaging in activities that reduce stress levels (de Bruin, 2021; Wilson et al., 2021). In contrast, younger adults are more concerned regarding their future lives and having greater access to information regarding the COVID-19 pandemic (Wang et al., 2020), including receiving less social support Li et al (2021) and uncertainty regarding working life (Pieh at al., 2020) resulted in lower levels of mental health. Similarly, a male reported to have better mental health due to less acknowledgment of their mental health issues (van Droogenbroeck et al., 2018), and female students may tend to report their mental health problems more common and quicker than their counterparts (Burger \& Scholz, 2018).

\section{Conclusion and Recommendation}

Discoveries from this study indicated that the Mental Health Inventory-Malay, consisting of 16 items is a reliable and valid instrument and likewise culturally appropriate to be administered to the intended Malaysian adult population. Outcomes reported good reliability and validity after eliminating two items (Item 2 and Item 16) that are considered to be too general in measuring mental health, resulting in low factor loadings. Findings also testified significant relationships between mental health with gender and age, with male and older adults having better mental health than their counterparts.

Conclusions from this study deliver implications and recommendations to the Ministry of Health, government and private health care institutions, non-government organizations, as well as research-related agencies on the administration of MHI-Malay to measure adults' mental health, particularly to the Malay-speaking community. MHI-Malay which is reliable and valid to be used in the Malaysian population, subsequently contains a small number of items (16 items) allow for a quicker mental health assessment than other existing mental health screening tools that have not yet been translated and validated to suit the Malaysian population.

Nonetheless, it is important to note that further research needs to be done to compile more pieces of evidence of its uses in different samples in Malaysia, being a multicultural country. Furthermore, future research should consider employing random sampling techniques and hard-copy instruments for data collection to gather more reliable data than convenient sampling and online surveys used in this study. 


\section{Acknowledgment}

This paper is the outcome of the research project conducted by the first author as a part of her sabbatical leave program granted by Sultan Idris Education University, Malaysia. The authors would like to extend their gratitude to Sultan Idris Education University and the University of Technology Malaysia, for the contributions made to this article. The MHI-Malay is available upon request from the first author.

\section{Reference}

Abdel-Khalek, A. M., \& Tekke, M. (2019). The association between religiosity, well-being, and mental health among college students from Malaysia. Revista Mexicana de Psicología, 36(1), 5-16.

Abdullah, N. H. (2021). Kenyataan Akhbar KPK 10 September 2021 - Sempena Hari Pencegahan Bunuh Diri Sedunia. From the Desk of the Director-General of Health Malaysia. https://kpkesihatan.com/2021/09/10/kenyataan-akhbar-kpk-10-september2021-sempena-hari-pencegahan-bunuh-diri-sedunia/

Al Mutair, A., Al Mohaini, M., Fernandez, R., Moxham, L., Lapkin, S., \& Ham-Baloyi, W. T. (2018). Psychometric testing of the Mental Health Inventory in an Arabian context: Cross cultural validation study. Nursing Open, 5(3), 376-383. https://doi.org/10.1002/nop2.149

Anjana, K. K., Suresh, V. C., Sachin, B. S., \& Poornima, C. (2021). The relationship between nomophobia, mental health, and coping style in medical students. Indian Journal of Social Psychiatry, 37(2), 207-211. https://doi.org/10.4103/ijsp.ijsp_213_20

Antazo, B. G. (2020). Psychometric evaluation of the differentiation of Self Inventory-Revised and Mental Health Inventory-18 for Filipinos. https://doi.org/10.31234/osf.io/mnc2f

Boas, A. A. V., \& Morin, E. M. (2014). Psychological well-being and psychological distress for professors in Brazil and Canada. Revista de Administração Mackenzie, 15(6), 201-219. https://doi.org/10.1590/1678-69712014/administracao.v15n6p201-219

Brislin, R. W. (1970). Back-translation for cross-cultural research. Journal of Cross-Cultural Psychology, 1(3), 185-216.

Burger, P. H. M., \& Scholz, M. (2018). Gender as an underestimated factor in mental health of medical students. Annals of Anatomy-Anatomischer Anzeiger, 218, 1 6. https://doi.org/10.1016/j.aanat.2018.02.005

Burns, R. A., Butterworth, P., \& Crisp, D. A. (2020). Age, sex and period estimates of Australia's mental health over the last 17 years. Australian \& New Zealand Journal of Psychiatry, 54(6), 602-608. https://doi.org/10.1177\%2F0004867419888289

Dahlberg L. (2021) Loneliness during the COVID-19 pandemic. Aging \& Mental Health, 25(7), 1161-1164. https://doi.org/10.1080/13607863.2021.1875195

de Bruin, W. B. (2021). Age differences in COVID-19 risk perceptions and mental health: Evidence from a national US survey conducted in March 2020. Journals of Gerontology: Series B, 76(2), e24-e29. https://dx.doi.org/10.1093\%2Fgeronb\%2Fgbaa074

Every-Palmer, S., Jenkins, M., Gendall, P., Hoek, J., Beaglehole, B., Bell, C., ... \& Stanley, J. (2020). Psychological distress, anxiety, family violence, suicidality, and wellbeing in New Zealand during the COVID-19 lockdown: A cross-sectional study. PLoS One, 15(11), e0241658. https://doi.org/10.1371/journal.pone.0241658

Gao, S., Mokhtarian, P. L., \& Johnston, R. A. (2008). Nonnormality of data in structural equation models. Transportation Research Record, 2082(1), 116-124.

Garson, G. D. (2012a). Structural Equation Modelling. Statistical Associates Publishing. 
Garson, G. D. (2012b). Testing Statistical Assumptions. Statistical Associates Publishing.

Geirdal, A. O., Ruffolo, M., Leung, J., Thygesen, H., Price, D., Bonsaksen, T., \& Schoultz, M. (2021) Mental health, quality of life, wellbeing, loneliness and use of social media in a time of social distancing during the COVID-19 outbreak. A cross-country comparative study. Journal of Mental Health, 30(2), 148-155. https://doi.org/10.1080/09638237.2 021.1875413

Grijak, D. (2017). Authenticity as a predictor of mental health. Klinička Psihologija, 10(1-2), 23-34. https://doi.org/10.21465/2017-KP-1-2-0002

Hair, J. F., Black, W. C., Babin, B. J., \& Anderson, R. E. (2010). Multivariate data analysis. ( $7^{\text {th }}$ ed.). Pearson.

Hair, J., Hult, T., Ringle, C., \& Sarstedt, M. (2014). A Primer on Partial Least Squares Structural Equation Modeling (PLS-SEM). Sage Publications, Inc.

Hassani, S. N., Tabiee, S., Saadatjoo, S. A., \& Kazemi, T. (2013). The effect of an educational program based on Roy Adaptation Model on the psychological adaptation of patients with heart failure. Modern Care Journal, 10(4), $459-467$. https://doi.org/10.1111/jjns.12255MANSOURI ET AL. 467.

Kumar, A., \& Nayar, K., R. (2021). COVID 19 and its mental health consequences. Journal of Mental Health, 30(1), 1-2. https://doi.org/10.1080/09638237.2020.1757052

Leijdesdorff, S., Klaassen, R., Wairata, D., Rosema, S., Amelsvoort, T. V., \& Popma, A. (2021). Barriers and facilitators on the pathway to mental health care among 12-25 year olds. International Journal of Qualitative Studies on Health and Wellbeing, 16(1). https://doi.org/10.1080/17482631.2021.1963110

Li, F., Luo, S., Mu, W., Li, Y., Ye, L., Zheng, X., ... \& Chen, X. (2021). Effects of sources of social support and resilience on the mental health of different age groups during the COVID19 pandemic. BMC psychiatry, 21(1), 1-14. https://doi.org/10.1186/s12888-020-030121

Massé, R., Poulin, C., Dassa, C., Lambert, J., Bélair, S., \& Battaglini, A. (1998). The structure of mental health: higher order confirmatory factor analyses of psychological distress and well-being measures. Social Indicators Research, 45, 475-504. http://dx.doi.org/10.1023/A:1006992032387

Meybodi, F. A., Saeedi, Z., Behjati, Z., Noorbala, F., Dastbaravardec, A., \& Enjedany, E. (2011). Reliability and validity of a Farsi version of 18 -item Mental Health Inventory. ProcediaSocial and Behavioral Sciences, 30, 1425-1429. https://doi.org/10.1 016/j.sbspro.2011.10.277

Kementerian Kesihatan Malaysia. (2021). Inisiatif perkhidmatan kesihatan mental dan sokongan psikososial (MHPSS) KKM. https://covid-19.moh.gov.my/semasakkm/2021/06/inisiatif-perkhidmatan-kesihatan-mental-dan-sokongan-psikososialmhpss-kkm

Mosher, C. E., Duhamel, K. N., Egert, J., \& Smith, M. Y. (2010). Self-efficacy for coping with cancer in a multiethnic sample of breast cancer patients: associations with barriers to pain management and distress. Clinical Journal of Pain, 26(3), 227-234. https://doi.org/10.1097/AJP.0b013e3181bed0e3

Mousavi, A., VaezMousavi, M., \& Yaghubi, H. (2015). Psychometric properties of the Persian version of Mental Health Inventory (MHI-38) in elite athletes. Sport Psychology Studies, 4(11), 27-40. 
Najma, R. U. A., \& Sultan, S. (2021). Role of procrastination in mental wellbeing and academic achievement through academic self-efficacy. Psychology and Education Journal, 58(4), 4088-4095.

Oyedeji, C. I., Hall, K., Luciano, A., Morey, M. C., \& Strouse, J. J. (2021). The Sickle Cell Disease Functional Assessment (SCD-FA) Tool: A feasibility pilot study. Research Square. https://doi: 10.21203/rs.3.rs-729092/v1.

Pieh, C., Budimir, S., \& Probst, T. (2020). The effect of age, gender, income, work, and physical activity on mental health during coronavirus disease (COVID-19) lockdown in $\begin{array}{llll}\text { Austria. Journal of Psychosomatic } & 110186 .\end{array}$ https://dx.doi.org/10.1016\%2Fj.jpsychores.2020.110186

Rafiq, M., \& Sadiq, R. (2019). Caregiver stress, perceived stigma and mental health in female family members of drug addicts: Correlational study. Journal of Pakistan Medical Association, 69(9), 1300-1306.

Rahman, M., \& Ahmed, O. (2018). Facebook use, Facebook addiction, and mental health of Chittagong university students. Bulgarian Journal of Science \& Education Policy, 12(2), $345-358$.

Ramayah, T., Cheah, J., Chuah, F., Ting, H., \& Memon, M. A. (2018). Partial Least Squares Structural Equation Modeling (PLS-SEM) using SmartPLS 3.0: An updated guide and practical guide to statistical analysis. ( $2^{\text {nd }}$ ed.). Pearson Malaysia Sdn. Bhd.

Reyes, M. E. S., Zantua, B. E. V., Nuñez, R. A. V., Manrique, W. S. M., \& Antonio, J. A. C. (2017). Exploring the mental health status of artistically gifted Filipino adolescents. North American Journal of Psychology, 19(2), 451-460.

Roslan, S. (2021). Lebih 120,000 panggilan isu kesihatan mental diterima. Harian Metro. https://www.hmetro.com.my/mutakhir/2021/05/708501/lebih-120000-panggilan-isukesihatan-mental-diterima

Schweda, A., Weismüller, B., Bäuerle, A., Dörrie, N., Musche, V., Fink, M., ... \& Skoda, E. M. (2021). Phenotyping mental health: Age, community size, and depression differently modulate COVID-19-related fear and generalized anxiety. Comprehensive Psychiatry, 104, 152218. https://doi.org/10.1016/j.comppsych.2020.152218

Seifert, T. A. (2005). The Ryff Scales of Psychological Well-Being. https://centerofinquiry.org/uncategorized/ryff-scales-of-psychological-well-being/

Smith C. L., Waters S. F., Spellacy D., Burduli E., Brooks O., Carty C. L., Ranjo S., McPherson S., \& Barbosa-Leiker C. (2021). Substance use and mental health in pregnant women during the COVID-19 pandemic. Journal of Reproductive and Infant Psychology. (17), 1-14. https://doi.org/10.1080/02646838.2021.1916815

Tabachnick, B. G., \& Fidell, L. S. (2007). Using multivariate statistics (5 $5^{\text {th }}$ ed.). Allyn and Bacon. Urbina, S. (2014). Essentials of psychological testing. John Wiley \& Sons.

Vaingankar, J. A., Abdin, E., van Dam, R. M., Chong, S. A., Tan, L. W. L., Sambasivam, R., ... \& Subramaniam, M. (2020). Development and validation of the Rapid Positive Mental Health Instrument (R-PMHI) for measuring mental health outcomes in the population. BMC Public Health, 20(1), 1-12. https://doi.org/10.1186/s12889-020-08569-w

van Droogenbroeck, F., Spruyt, B., \& Keppens, G. (2018). Gender differences in mental health problems among adolescents and the role of social support: results from the Belgian health interview surveys 2008 and 2013. BMC Psychiatry, 18(1), 1-9. https://doi.org/10.1186/s12888-018-1591-4

Veit, C., \& Ware, J. (1983). The structure of psychological distress and well-being in general populations. Journal of Consulting and Clinical Psychology, 51, 730-42. 
Wang, Y., Kala, M. P., \& Jafar, T. H. (2020). Factors associated with psychological distress during the coronavirus disease 2019 (COVID-19) pandemic on the predominantly general population: A systematic review and meta-analysis. PloS One, 15(12), e0244630. https://doi.org/10.1371/journal.pone.0244630

Wilson, J. M., Lee, J., \& Shook, N. J. (2021). COVID-19 worries and mental health: the moderating effect of age. Aging \& Mental Health, 25(7), 1289-1296. https://doi.org/10.1080/13607863.2020.1856778

Worldometer. (2021). Covid-19 Coronavirus Pandemic. https://www.worldometers.info/coronavirus/

World Health Organization. (2018). Mental health: strengthening our response. https://www.who.int/news-room/fact-sheets/detail/mental-health-strengtheningour-response 